\title{
LUCHA Y RESISTENCIA DE LAS MUJERES NEGRAS EN LA CARRERA RELIGIOSA EN BRASIL: EL ANÁLISIS DE CASO \\ DE LAS HERMANAS NEGRAS DE LA CONGREGACIÓN DE LAS HERMANAS MISIONERAS DE JESÚS CRUCIFICADO
}

\section{The fight and resistance of black women in religious careers in Brazil: the case of the black sisters of the Congregation of the Missionary Sisters of Jesus Crucified}

\author{
Maria Aparecida Corrêa Custódio \\ Universidad Federal de Maranhão, Brasil
}

\begin{abstract}
Resumen: Este artículo tiene como objetivo analizar la narrativa histórica de las hermanas negras de la Congregación de las Hermanas Misioneras de Jesús Crucificado, poniendo foco en la discusión sobre la carrera religiosa en la primera mitad del siglo xx, época marcada por el prejuicio y la discriminación racial tanto en la Iglesia católica como en la sociedad brasileña. Se pretende, así, traer las voces y dialogar con mujeres que dejaron muchos rastros de resistencia y tomaron el control de sus propias vidas. Acogidas por la congregación de Jesús Crucificado, la única en Brasil que adoptó una política vocacional que permitía el ingreso de mujeres negras, ellas entraron en un campo de luchas por el derecho a la igualdad racial y religiosa que no se alcanzó hasta la segunda mitad del siglo $x x$.
\end{abstract}

Palabras clave: congregación religiosa femenina, discriminación racial, emancipación femenina negra, historia, siglo xx.

Abstract: This article analyzes the historical narrative of black members of the Sisters of Jesus Crucified congregation, focusing on the discussion of religious careers in the first half of the 20th century, a time marked by prejudice and racial discrimination both in the Catholic Church and in Brazilian society. It aims, therefore, to examine the voices of and present dialogues with women who left behind many examples of resistance and agency in their own lives. Welcomed into the Congregation of the Missionary Sisters of Jesus Crucified, the only Brazilian congregation that adopted a vocational policy that allowed black women 
to enter, they came up against a field of struggles for the right to racial and religious equality, only recently achieved in the second half of the 20th century.

Keywords: female religious congregation, racial discrimination, black female emancipation, history, written narrations.

\section{Introducción}

Este artículo es el resultado de una invitación del Núcleo de Estudos e Pesquisas Interdisciplinares da África e dos Afro-brasileiros de la Universidad Federal de Tocantins (campus de Tocantinópolis), para contribuir con la Semana Nacional de la Conciencia Negra (2019) y discutir temas de un segmento un tanto invisible en los debates académicos: las hermanas negras y sus procesos de liberación y emancipación. De este rico intercambio surgió este texto, cuyo tema fue una casualidad en mi investigación doctoral, que se centró en la formación y trayectoria de una congregación femenina brasileña en el área de la inmigración italiana. Este hallazgo - la historia de la mujer negra en la vida religiosaya no abandonó los horizontes de investigación de esta autora, aun cuando su lugar de discurso es el de quien reconoce que pertenece a un grupo que tiene los privilegios de la blancura, pero que se compromete en la lucha antirracista.

La Congregación de las Misioneras de Jesús Crucificado fue fundada en 1928, en la ciudad de Campinas (São Paulo), y sus precursores fueron la joven María Villac y el obispo Francisco Campos Barreto. En 1919, María Villac comenzó a reunir a un grupo de mujeres de distintas edades para desarrollar prácticas de meditación, animar a la oración en familia ante la cruz y ayudar a las personas más necesitadas. Estos grupos, formados predominantemente por mujeres, recibieron el nombre de Asociación de Misioneros Externos/Externas (AME), y más tarde darían origen a la Congregación de las Misioneras de Jesús Crucificado, cuya misión era evangelizar y asistir a los pobres de la periferia de Campinas (Silva, 2016). María Villac también se dedicó al apostolado con las mujeres negras, y probablemente fue por este contacto que surgió la idea de incluir a niñas negras en la nueva congregación, pero en la clase de las hermanas oblatas (Azzi, 2008: 88).

Este artículo aborda la historia de las religiosas negras de la Congregación de las Hermanas Misioneras de Jesús Crucificado (CIMJC), la 21. ${ }^{a}$ congregación femenina de vida activa creada en Brasil y la primera en promover una política vocacional de reclutamiento de niñas negras para la vida religiosa (Beozzo, 1983; Beozzo et al., 2009). El objetivo del estudio es analizar la narrativa histórica de las hermanas negras de la Congregación, centrándose en la cuestión de la carrera religiosa que recorrieron a lo largo del siglo xx, marcada por muchas luchas por el derecho a la igualdad racial y religiosa dentro de la propia congregación. El tema cobra relevancia por el hecho de tratarse de la única congregación femenina brasileña que adoptó una política vocacional que permitió el ingreso de mujeres negras, indígenas, mulatas y pardas, práctica que sería ejemplar 
si no hubiera reproducido una especie de casa de esclavos - senzala - en su seno. ${ }^{1}$

Para comprender mejor lo que significó para las mujeres negras vivir como hermanas oblatas, dentro de la congregación de Jesús Crucificado, hasta la década de 1960, y en qué sentido las reformas del Concilio Vaticano II (1962-1965) impactaron en sus vidas, hacemos una reinterpretación de historia escrita por religiosas negras y publicada en una obra colectiva. Se trata de la narrativa histórica de José O. Beozzo, M. Raimunda Costa, Maria F. do Espírito Santo y Geralda F. Silva, publicada en 2009 y poco explorada en estudios académicos (Custódio, 2011), así como del tema de la vida religiosa negra en Brasil (Fonseca, 2000).

La hipótesis es que la relectura de este trabajo permite plantear algunas cuestiones que se mantuvieron en la clandestinidad en la historia de la vida religiosa brasileña, las cuales pueden ser encontradas en los testimonios escritos, entrevistas, cartas, informes, estadísticas de la congregación y comentarios relevantes, en este caso de las autoras étnicamente negras, que fueron publicados en dicho libro colectivo. Así, la relectura permite explorar evidencias presentes especialmente en los testimonios escritos y entrevistas que revelan procesos discriminatorios y, al mismo tiempo, emancipatorios vividos por las religiosas negras.

Para abordar esta cuestión se adopta un enfoque teórico-metodológico que relee analíticamente la narrativa histórica desde la perspectiva del paradigma propuesto por Carlo Ginzburg (1989). ${ }^{2}$ De hecho, intentamos hacer uso de algunas de las tesis del autor, como la observación de posibles pistas dejadas entre líneas de esa narrativa histórica, resaltando evidencias (aparentemente marginales) presentes en cartas, informes y estadísticas de la congregación que podrían pasar desapercibidas porque estos documentos fueron publicados en los anexos del libro.

Si se lee bien entre líneas, esa narrativa es un hito en la revelación de los entresijos de la vida religiosa femenina negra en Brasil. Por ello, se pretende traer aquí las voces y hablar con estas mujeres que, si bien fueron ubicadas al margen de la sociedad de su tiempo, dejaron muchos rastros de resiliencia en su historia, la cual solo se insertó en la historia oficial de la Congregación de las Hermanas Misioneras de Jesús Crucificado pasados ochenta y un años de existencia de la institución.

Este trabajo es un esfuerzo realizado por las propias misioneras ex-oblatas [negras] para rescatar su propia historia, su contribución a la trayectoria de la Congregación y su compromiso en la formación del Movimiento de las Hermanas Negras [...]. Este grupo también se siente parte

1. En Brasil, el sistema de clasificación racial utilizado por el Instituto Brasileño de Geografía y Estadística (IBGE) es el de «color o raza». El término «pardo» designa a la población mestiza con mezclas de colores en la piel.

2. Ginzburg sugiere leer entre las líneas de la documentación de archivo. Propone buscar fuentes novedosas con la perspectiva de desentrañar pistas y signos, valorar hallazgos aparentemente marginales pero provocadores y desencadenantes de una curiosidad que propicia el desarrollo de la investigación. 
de un movimiento más general de grupos afrobrasileños dentro y fuera de las Iglesias, en conexión con movimientos similares en otros países de América Latina y el Caribe y en articulación con sus raíces y culturas presentes en los países de la Madre África (Beozzo et al., 2009: 69-70).

Esta obra pasó por un arduo proceso de producción. El proyecto de rescatar la historia de las hermanas negras se inició a finales de la década de 1980 y se reforzó en 2001 cuando las hermanas solicitaron el asesoramiento del sacerdote-historiador José Oscar Beozzo; sin embargo, no finalizó hasta 2008-2009. La demanda surgió como resultado de la constatación de que toda la documentación escrita de la congregación había sido producida por hermanas no negras, que silenciaron la historia de las hermanas negras. Es decir, hasta 2009, los que estaban autorizados para narrar la historia de la Congregación de las Hermanas Misioneras de Jesús Crucificado eran sujetos blancos.

La pregunta que surge para quienes recorren la documentación es la siguiente: ¿por qué, tanto Dom Barreto [obispo fundador] como María Villac [fundadora], al describir los inicios de la Congregación, pusieron en su origen la Asociación de las Misioneras de Jesús Crucificado, pero nada se dice sobre ese otro grupo de «mozas de color» [hermanas negras] [...]. ¿Por qué, asimismo, se recuerda siempre como fundadores del Instituto a los ocho que ingresaron el primer día, pero no a la novena [inegra!], que se unió justo el mismo día para iniciar, como oblata, la Congregación de las Misioneras de Jesús Crucificado? (Ibídem: 56-57).

A partir de estos cuestionamientos, construidos y ampliados en los encuentros de articulación del grupo de hermanas negras de la congregación, que comenzaron en 1983, se creó una comisión para producir documentos orales y escritos (entrevistas, mesas redondas, cartas, relatos y informes) y sistematizar los datos del archivo histórico de la congregación. Los trabajos fueron tan prometedores que en el V Encontro de Irmãs Negras da Congregação das Irmãs Missionárias de Jesus Crucificado, celebrado en 1996, estas mujeres lograron rescatar e insertar a tres fundadoras negras en la historia del instituto: Maria do Espírito Santo Ferreira (1890-1950), Lydia Maria da Conceição Pompeu (18951996) y Anésia Maria Miquelina de Andrade (1905-1967), que no aparecían en la versión oficial. De esta manera, conquistaron su lugar de habla, refutando la historiografía institucional y los saberes históricos provenientes de la jerarquía religiosa.

Esa historiografía negra contiene memorias reconstruidas de un pasado no muy lejano, permeado por imágenes e ideas de un presente consciente de la negritud. Los recuerdos son narrados a partir de experiencias personales, que también están estructuradas por las percepciones de sus pares. Aunque las ideas de Hallbwachs (2017: 33) no se evocan en la narrativa histórica de las hermanas negras de Jesús Crucificado, las premisas de este autor pueden llevar a entender que la memoria individual de las hermanas negras es una memoria social y colectiva.

Parafraseando a Hallbwachs, la reconstrucción de la memoria de las hermanas negras se operó a partir de datos o nociones comunes que se encuentran tanto en su propio espíritu como en el de sus otras compañeras, lo cual solo es 
posible porque formaron parte de la misma sociedad (o grupo de hermanas negras de la congregación). Y, parafraseando a las feministas negras, se afirma que las hermanas negras, al haber ocupado el mismo espacio social en la Congregación de las Misioneras de Jesús Crucificado, compartieron experiencias comunes en las relaciones de poder religioso (Ribeiro, 2019a: 64).

Al reinterpretar la narrativa histórica de las hermanas negras de Jesús Crucificado, este artículo discute evidencias captadas en testimonios escritos y entrevistas con religiosas que enfrentaron discriminación de color y fueron colocadas en la vida religiosa como el otro del otro. Este artículo también destaca las evidencias que muestran la lucha de las religiosas negras por la igualdad racial en la congregación de Jesús Crucificado y la conquista de su lugar de habla en el contexto del movimiento de renovación de la vida religiosa desatado por el Concilio Vaticano II. Todas estas conjeturas se analizan a la luz de algunos conceptos de género y raza articulados en relación con las cuestiones planteadas por el feminismo negro (Carneiro, 1995; Gonzalez, 1984; 2011).

\section{Mujer negra en la vida religiosa: el otro del otro}

En Brasil, el feminismo negro ha encontrado una forma muy didáctica de socializar la investigación científica para un gran público de lectores y lectoras: fue elegido como el primer tema de la colección de Feminismos Plurales, lanzada en 2017, bajo la coordinación de Djamila Ribeiro, filósofa, profesora, escritora y activista social. Se trata de «una serie de libros imprescindibles cuando pensamos en producciones intelectuales de grupos históricamente marginados", lo que significa también difundir estudios de autoras y autores negros (Ribeiro, 2019a: 13). El debate se extiende a las redes sociales a través de una plataforma digital y un canal de YouTube, ambos titulados Feminismos Plurais.

La expresión «el otro del otro» se toma prestada del feminismo negro, un movimiento que resalta la invisibilidad de las mujeres negras y que afirma que la mujer negra es el otro del otro. Esta declaración es una relectura del concepto clásico de Simone de Beauvoir (2009) - la mujer como el otro, mero objeto que no tiene la reciprocidad de la mirada del hombre - hecha por Grada Kilomba (2012) en la perspectiva de que la mujer negra es el otro del otro, es decir, que se halla en una posición de difícil reciprocidad.

Así las mujeres negras fueron puestas en varios discursos que tergiversan nuestra propia realidad: un debate sobre el racismo donde el sujeto es un hombre negro; un discurso de género donde el sujeto es la mujer blanca; y un discurso sobre la clase donde la «raza» no tiene cabida. Ocupamos un lugar muy crítico, en teoría. Es por esta carencia ideológica, sostiene Heidi Safia Mirza (1997), que las mujeres habitan un espacio vacío, un espacio que se superpone a los márgenes de «raza» y de género, el llamado «tercer espacio» (Ibídem: 56).

Según este pensamiento, la hegemonía masculina blanca prevalece sobre la hegemonía femenina blanca y ambas sobre la hegemonía masculina negra, aunque el estatus de las mujeres blancas y de los hombres negros sea oscilante. El último lugar lo ocupan las mujeres negras. Esta pirámide socio-racial es muy vi- 
sible especialmente en el ámbito laboral. Según una investigación realizada en 2016 por el Instituto de Investigaciones Económicas Aplicadas, las mujeres blancas ganaban alrededor del $30 \%$ menos que los hombres blancos; los hombres negros ganaban menos que aquellas; y las mujeres negras, menos que todos los grupos citados (Ribeiro, 2019a: 39-40).

Esta situación analizada por Djamila Ribeiro era un poco más grave en la Congregación de las Misioneras de Jesús Crucificado en la primera mitad del siglo xx: en primer lugar, prevalecía la hegemonía masculina blanca eclesiástica; en segundo lugar, la hegemonía femenina blanca en la dirección del instituto; en tercer lugar, la hegemonía femenina blanca en las casas religiosas; y, por último, estaban las religiosas negras, que eran las últimas de las últimas. Lógicamente, ese cuadro cambió en el proceso de unificación de las clases de hermanas, a partir de 1965; sin embargo, debido a las posiciones de género ocupadas por hombres y mujeres en el catolicismo, aún podemos observar la hegemonía masculina en la cúspide de la pirámide eclesial: en definitiva, los obispos y sacerdotes continúan dirigiendo a las hermanas y sus instituciones.

La Congregación de las Hermanas Misioneras de Jesús Crucificado surgió en una época en la que los negros eran discriminados por los institutos religiosos y excluidos de sus cuadros. Y no fueron solo los católicos los que excluyeron a los negros: también había restricciones entre los mormones para el acceso de los negros al sacerdocio y descalificación simbólica de su raza entre los espiritistas. El historiador Riolando Azzi hace la siguiente declaración:

[...] como analiza Délcio Monteiro de Lima, el trabajo de «seducción para las filas del mormonismo" encontró por delante «la barrera del prejuicio racial en relación con los negros», debido a la prohibición de acceso al sacerdocio [...].

Es interesante observar que también los espiritistas brasileños incorporaron en su doctrina la misma concepción católica de que el color negro era un signo de castigo y maldición [...].

Dentro de la perspectiva de la reencarnación, los negros estarían pagando ahora por los pecados cometidos en vidas anteriores, y el color negro era exactamente la expresión visible de ese mal anterior.

Se adopta, por lo tanto, una simbología similar a la de la Iglesia Católica, siendo el blanco el símbolo de la gracia y el negro la expresión del pecado. Como telón de fondo, el prejuicio racial (Azzi, 2008: 90-91).

En general, se vivía un racismo estructural en la sociedad brasileña que afectaba a todas las instituciones sociales. Las instituciones no adoptaban prácticas antirracistas; por el contrario, muchas veces silenciaban, reproducían o negaban el racismo en su organización (Almeida, 2019). Las congregaciones religiosas femeninas, en la primera mitad del siglo xx, solo recibían a jóvenes negras si eran objeto de ayudas caritativas, empleadas de los conventos o preferentemente hermanas oblatas (también llamadas hermanas conversas o legas), una especie de segunda clase; en la primera clase, estaban las hermanas de coro. La clase de las hermanas oblatas estaba constituida por mujeres que querían seguir la vida religiosa, pero no eran consideradas "capaces de ejercer todos los oficios» dentro de una congregación, por presentar alguna deficiencia física, dificultad intelectual o impedimento de cualquier otra índole, como era conside- 
rada la cuestión del color, en el caso de las mujeres negras. Por esta razón, solo les estaba permitido "ayudar a las Hermanas [de coro] en el trabajo más duro».3

En 1953, una investigación monográfica realizada por una misionera de Jesús Crucificado, sor Sylvia Maria do Calvário Villac, a través de un cuestionario enviado a las superioras generales y superioras provinciales de las congregaciones en Brasil, aporta claras evidencias del lugar de las mujeres negras en la vida religiosa, a pesar de que las congregaciones estaban experimentando una serie de transformaciones en la década de 1950 (Villac, 1953). Esta investigación fue mencionada en la narrativa histórica bajo análisis y presenta el siguiente resultado: el $88,88 \%$ de las congregaciones dijeron que recibieron a mujeres negras para formar la clase de hermanas oblatas. Sin embargo, solo el $22,20 \%$ de las congregaciones dijeron que recibieron a mujeres negras para ser parte de la clase de hermanas de coro. El $43,75 \%$ de las congregaciones dijeron que no tenían la intención de recibir a candidatas negras en el futuro y el $37,50 \%$ no respondió a la pregunta. Aun así, el $50 \%$ de las congregaciones manifestó que no existía prejuicio racial entre las hermanas, lo cual resulta, cuanto menos, extraño, en vista de los datos obtenidos.

Muchas congregaciones no abolieron la clase de hermanas legas hasta después de la actualización de la vida religiosa tratada por el Concilio Vaticano II (1962-1965), aunque hubo llamamientos papales para que esta práctica se extinguiera -Benedicto XV (1919), Pío XI (1926) y Pío XII (1951)-, en un intento por resolver los problemas derivados de la división por clases que afectaba a religiosos europeos y nativos en China, Asia y África.

Como ya se dijo, a pesar de este contexto sociocultural, la Congregación de las Hermanas Misioneras de Jesús Crucificado apostó por una política vocacional que promovió el reclutamiento de cientos de mujeres negras desde 1928. Fue una iniciativa cuyos orígenes se remontan al período anterior a la fundación de la Congregación y se debe a la acción de María Villac, laica cristiana que se convirtió en fundadora y primera superiora general de la congregación.

La contradicción se estableció en ese momento, ya que el apostolado coordinado por María Villac era una asociación religiosa que reunía a mujeres blancas y negras dedicadas al catecismo de niños y adultos, las visitas domiciliarias y otras prácticas comunitarias. Sin embargo, cuando se las invitaba a unirse a la categoría de oblatas, pasaban a dedicarse exclusivamente a las tareas internas, domésticas y más pesadas de la congregación, dejando el apostolado. Con el tiempo, las candidatas negras se darían cuenta de que el ardor misionero que las había llevado a incorporarse a la nueva congregación les traería un sabor amargo de vida confinada y marcada por la discriminación racial, mitigada por una salmodia que es recurrente en los testimonios: «Esto tiene que terminar, eso va a terminar. ¡Seamos pacientes! Esto terminará» (Beozzo et al., 2009: 163, 265).

3. Datos históricos del Archivo de Historia de la Congregación de las Hermanitas de la Inmaculada Concepción (São Paulo), publicados en 1990: Coletânea Histórica da Congregação das Irmãzinhas da Imaculada Conceição, págs. 401-404. 
Por otro lado, la acción de recibir candidatas negras fue bien recibida por la población negra, pues atendía una demanda reprimida en la Iglesia católica y este hecho no parece ser una casualidad en la historia. Campinas, donde la congregación nació y se consolidó, fue un reducto de esclavos en el siglo xIX. Desde la década de 1870, Campinas era un importante productor de café y empleaba mano de obra esclava (Maciel, 1985).

En el censo de 1872 se constató que la población negra constituía la mayoría de los habitantes del municipio de Campinas, SP [...]. Mientras que en todo el país era claro el declive de la población esclava, luego de la interrupción del comercio de esclavos, Campinas seguía aumentando su plantel, importando esclavos de otras regiones a causa de la expansión y riqueza de su agricultura del café. En 1874, el municipio de Campinas concentraba el mayor número de esclavos de toda la provincia de São Paulo: 13.685 [...]. En 1882, el número de esclavos en Campinas había aumentado de 13.000 a 15.665, un aumento de casi 2.000 nuevos esclavos. En el momento de la abolición, a pesar de la creciente afluencia de inmigrantes europeos, el número de esclavos se mantenía en esos mismos altos niveles (Beozzo et al., 2009: 409-410).

Esta especificidad de Campinas tuvo un gran impacto en la forma en que se trató a la población negra en el período posterior a la abolición y en la forma en que reaccionó: se tienen noticias de la prensa negra en Campinas con circulación de varios periódicos desde 1903 según el estudio de Tiede (2018). Se tienen noticias también de la creación de sociedades culturales de negros (como el Centro Cívico Palmares) y de la participación de mujeres negras en asociaciones religiosas, el apostolado de las Hijas de María y otros grupos comunitarios.

En este contexto, la propuesta de la nueva congregación, con seguridad, favorecería principalmente a mujeres negras de la región de Campinas y de otros lugares del país donde había explotación de mano de obra esclavizada y formación de numerosas familias afro-descendientes. Prueba de ello son los datos presentados en la narrativa histórica (Beozzo et al., 2009: 551, 554), que muestran el elevado número de mujeres negras en la congregación. Entre los años 1928 y 1965, 554 hermanas negras hicieron la profesión de votos. En el mismo período, 402 hermanas pardas o mulatas tomaron los votos. Pero solo 260 hermanas blancas hicieron los votos. Todas estas hermanas estaban destinadas a la clase de las hermanas oblatas. Agrupando negras y pardas se verifica la mayoría abrumadora de mano de obra afrodescendiente en esa congregación. Así, sumando negras, pardas y blancas, estas últimas en menor proporción (eran hijas de colonos de la región sur del Brasil, con pocos años de estudio), se constata que un número significativo de mujeres estuvieron en la vanguardia de los trabajos duros. Siempre según lo recogido en Beozzo et al, (2009) el trabajo de las religiosas negras era la base de sustentación de la congregación en varios frentes: trabajo doméstico (que incluía el suministro de leña para los fogones), costura, bordado y zapatería para uso interno; cultivos y cría de aves y cerdos; trabajo gráfico para la elaboración de boletines y otros materiales de la congregación; producción culinaria y artesanal para consumo interno y venta externa; venta de productos alimentarios y artesanales en las calles, escuelas, oficinas 
públicas y comerciales, realizado en forma ambulante; venta de la revista de la congregación, puerta a puerta; y pedidos de limosna en canteras y depósitos de material de construcción.

Sin embargo, la narrativa de la historia hizo una reinterpretación crítica de estos trabajos serviles.

\begin{abstract}
Esos trabajos eran vistos como una "pérdida de tiempo" [dijeron las hermanas de coro] que perjudicaría la dedicación del Instituto a su objetivo principal: el apostolado. Así, las hermanas legas, asumiéndolos, liberarían el tiempo de las hermanas de coro para esta tarea superior y que, por eso mismo, las ennoblecía. Lo contrario también era cierto, ya que las tareas de las oblatas o legas, lejos de ennoblecerlas, las devaluaban y disminuían, afectando directamente su autoestima, cuanto más porque todos sus esfuerzos y sacrificios eran, en general, poco valorados y reconocidos (Ibídem: 256).
\end{abstract}

No es posible olvidar el hecho de que este tipo de trabajo estaba entrelazado con el lugar social subordinado que ocupaban en la congregación y en la sociedad. Tanto es así que ellas llamaban la atención de la comunidad católica cuando participaban en ritos públicos: en las procesiones de Corpus Christi eran notadas por las damas de la élite de Campinas, que comentaban que se sentían perjudicadas en la supuesta disputa de mano de obra negra con las señoras de la congregación.

Cuando pasaban las hermanas oblatas, en una larga fila, porque entre postulantes y novicias eran las más numerosas, a veces escuchaban comentarios rencorosos de las señoras de la sociedad: - ¡Miren eso! Por eso ya no conseguimos más empleadas domésticas. ¡María Villac se las está robando todas! (Ibídem: 268).

Estos comentarios provocaron la indignación de don Francisco de Campos Barreto, obispo fundador de la Congregación, quien proclamaba: «Las hermanas oblatas, o hermanas conversas, del Instituto no son lo que se piensa erróneamente por ahí. Simples amas de casa, sirvientas de misioneras de hábito azul. ¡No! ¡No!» (Ibídem: 233). Para el obispo, la cuestión podría resolverse en términos de manipulación teológico-simbólica. Así, las hermanas negras eran concebidas como verdaderas religiosas, pero constituían una sección separada, según las reglas instituidas por él. Este tipo de precepto prevaleció hasta 1956, como decía el artículo 9 de las Constituciones de la Congregación: «Todas las hermanas, sin embargo, forman una sola familia religiosa, disfrutan de las mismas indulgencias, privilegios y gracias espirituales y, al morir, tienen derecho a los mismos sufragios. Todas están igualmente obligadas a observar las Constituciones y la disciplina religiosa común» (Ibídem: 282). Probablemente se esperaba que las oblatas formaran un cuerpo dócil y homogéneo, como se muestra en las figuras 1 y 2 . 
Figura 1. Grupo de hermanas y postulantes legas con los fundadores de la congregación - s.d., c. mediados del siglo xx.

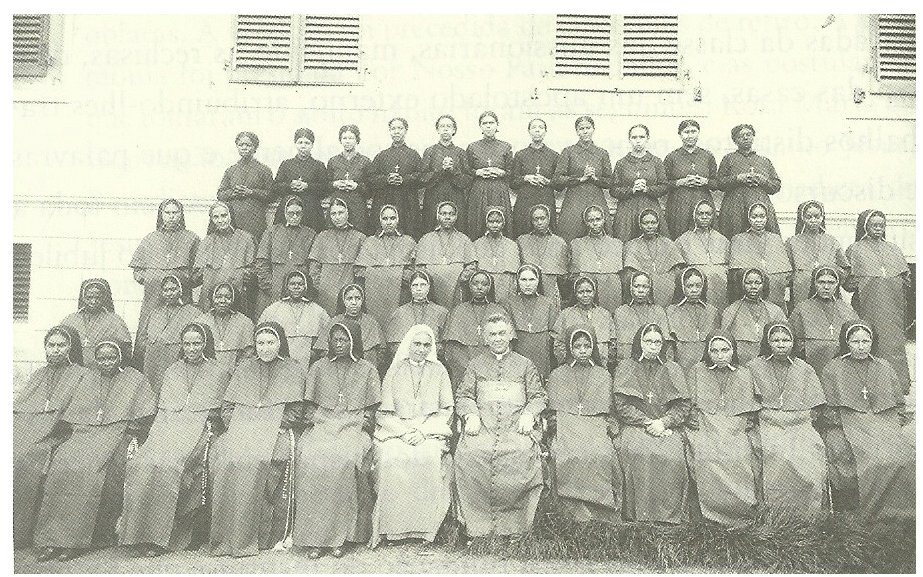

Fuente: Beozzo et al. (2009: 66).

Figura 2. Hermanas oblatas con hábitos (sentadas) y en ropa de calle (de pie) - s.d., c. mediados del siglo xx.

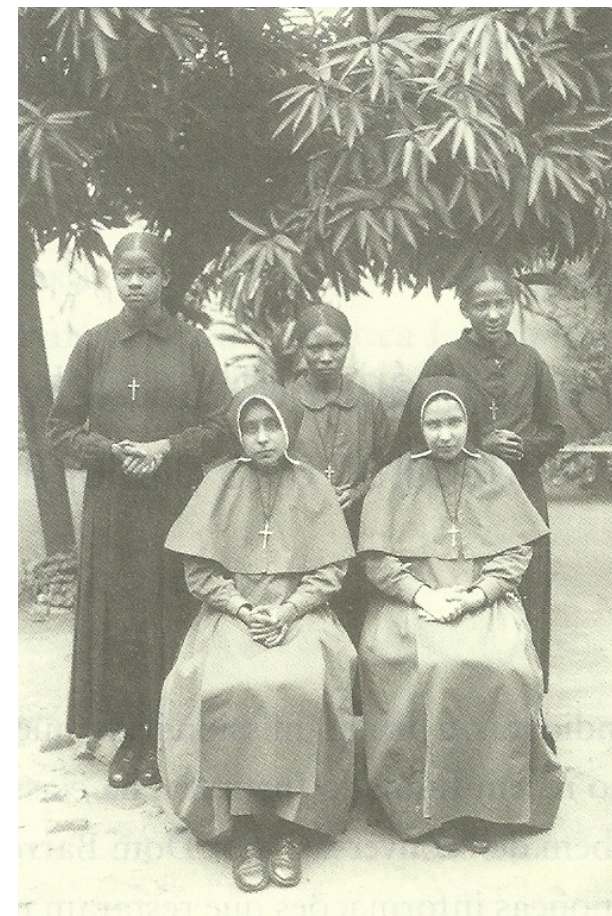

Fuente: Beozzo et al. (2009: 72). 
La trayectoria seguida por las mujeres negras que se postulaban para la incorporación a la congregación seguía rutas diferenciadas respecto de la de las mujeres blancas. La diferencia se encontraba ya desde el inicio, pues había dos libros de registros, uno para las mujeres negras y otro para las mujeres blancas cultas, lo que recuerda los antiguos libros de bautismo que separaban a esclavos y hombres libres. Las postulantes negras hacían el noviciado separadas de las demás, con un currículo y maestras diferentes; no tenían voz ni voto en las instancias de toma de decisiones de su congregación; a menudo dormían en el sótano de las casas; hasta 1953, recibían un anillo de plata en el rito de consagración perpetua (después comenzaron a recibir un anillo de oro, como las hermanas de coro); vestían un hábito más modesto (el hábito elegante era el de las misioneras de primera clase). No podían estudiar, ni trabajar en el apostolado, ni hacer muchas otras cosas, durante la primera mitad del siglo xx.

Algunos pasajes de la narrativa, referida al período 1928-1965, sobre los temas de vocación religiosa, itinerario, clase, color y raza en la congregación, impactan a cualquier lector con relatos de vivencias inimaginables en conventos del siglo xx. En otras palabras, los testimonios indican que la congregación religiosa reprodujo la discriminación racial vigente en la sociedad brasileña. Estos testimonios, producidos y editados por las hermanas negras y su asesor histórico, terminaron generando un análisis que brinda aún más información sobre la dureza de ser mujer negra en la vida religiosa de la primera mitad del siglo xx.

\footnotetext{
Las oblatas, si llegaban analfabetas, analfabetas continuarían, ya que no había ninguna preocupación en alfabetizarlas o enviarlas a la escuela, para que completasen sus estudios, mientras que se hacía un esfuerzo constante a favor de las candidatas de coro para que continuaran sus estudios y estuvieran preparadas para asumir muy pronto responsabilidades de docencia, formación y gestión. Esta situación comenzó a cambiar solo después de la unificación de las clases (lbídem: 238).

En el mejor de los casos, las oblatas podrían ser promovidas de auxiliar de cocina a cocinera; de auxiliar de costura a costurera; de auxiliar de zapatera a "oficial de zapatería».

Ciertos trabajos eran considerados no solo despreciables sino incluso repulsivos. Las oblatas que debían, por ejemplo, encargarse del lavado de la ropa y del chiquero. Maria Lina da Costa, más conocida como Sor Maria das Dores, cuidó de los cerdos durante treinta y cinco años. En un principio, Sor Maria das Dores iba al chiquero, cuidaba a los cerdos, pero volvía para hacer las comidas en comunidad y participar de la vida del grupo. Más tarde, cuando se agudizó el conflicto interno dentro de la Congregación, que eventualmente desembocaría en su división, con el surgimiento de la provincia autónoma, la religiosa comenzó a alejarse de la comunidad y a pasar cada vez más horas entre los cerdos [...]. Solo volvía por la noche a dormir (Ibídem: 259-260, 264).
}

Cabe aclarar que el conflicto interno mencionado en la historia de sor Maria das Dores llevó a la división de la congregación y a la creación de una provincia autónoma, problemática que surgió en el contexto de la renovación de la vida religiosa que trajo el Concilio Vaticano II. El grupo más alineado con el Concilio permaneció en la Congregaçión de las Hermanas Misioneras de Jesús Crucificado -objeto de este artículo- y el grupo más ligado al tradicionalismo y al conservadurismo fundó el instituto de las Misioneras de Jesús Crucificado, reconocido oficialmente por la Santa Sede en 1994. 
Un análisis psicológico del significado de la discriminación, la segregación y el estatus religioso en la vida de las hermanas negras de Jesús Crucificado escapa al alcance de este ensayo, en términos de abordaje y recorte temático, pero las evidencias son manifiestas en las declaraciones que se generaron en las rondas de conversación, y en las entrevistas individuales o escritas por las propias hermanas. Por ahora, es posible inferir que, durante muchas décadas, las hermanas negras constituyeron el otro del otro en la Congregación de las Misioneras de Jesús Crucificado, lo que probablemente no fue diferente en otras instituciones católicas de la época.

\section{El lugar de habla de la religiosa negra}

El «lugar de habla» es otra expresión tomada del feminismo negro, un concepto entretejido con consideraciones teóricas, en particular, de Patricia Collins (2019) y Grada Kilomba (2012). Este concepto lo retoma Djamila Ribeiro:

[...] no existe una epistemología definida sobre el término «lugar de habla» específicamente, o mejor dicho, el origen del término es impreciso. Creemos que la expresión surge a partir de la tradición de discusión sobre el feminist standpoint - en una traducción literal «punto de vista feminista» - diversidad, teoría racial crítica y pensamiento descolonial. Las reflexiones y el trabajo generado en estas perspectivas, en consecuencia, se fueron configurando en el seno de los movimientos sociales, muy marcadamente en el debate virtual, como herramienta política y con la intención de oponerse a una autorización discursiva (Ribeiro, 2019a: 57).

Esa autorización discursiva se refiere a una narrativa autorizada que presenta una visión universal de la mujer, sin considerar las distinciones de cada mujer a partir del lugar que ocupa en la sociedad. Por el contrario, es necesario considerar que cada persona es un lugar de habla y que cada una habla desde un lugar social y desde las condiciones sociales que se les dan para acceder o no a la ciudadanía.

El concepto de lugar de habla discute precisamente el locus social, es decir, de qué punto las personas parten para comenzar a pensar y a existir en el mundo, de acuerdo con sus experiencias comunes. Esto es lo que nos permite valorar en qué medida un grupo determinado - dependiendo de su lugar en la sociedad - sufre obstáculos o está autorizado y favorecido (Ribeiro, 2019b: 35). ${ }^{4}$

A partir de este pensamiento podemos analizar el caso de las religiosas negras de Jesús Crucificado: una hermana negra tiene experiencias diferentes de las de una hermana blanca por su ubicación en el espacio social y porque vive el género de otra manera. Por tanto, decimos que tiene una visión diferente de la vida religiosa y de la propia congregación a partir del lugar que ocupa y de su ubicación en las relaciones jerárquicas de poder. En este sentido, las hermanas

4. La cursiva en el original. 
negras de Jesús Crucificado comparten una experiencia común: no pudieron participar de manera justa en la congregación en la primera mitad del siglo xx y tuvieron que luchar por el derecho a la igualdad racial y religiosa en la segunda mitad del mismo siglo.

Una cuestión ineludible es preguntarse por qué permanecieron en una congregación religiosa si eran tratadas como el otro del otro. ¿Cómo resistieron ese racismo religioso? Según se desprende de la narrativa histórica, ellas se apropiaron de las orientaciones eclesiales emanadas del Concilio Vaticano II en favor de sus propios procesos de emancipación. Sin duda, el contexto occidental de la segunda posguerra fue favorable porque hubo un cambio de paradigma en relación con la necesidad de formar un ser humano y ciudadano menos prejuicioso y no autoritario, más respetuoso con las etnias y más consciente del racismo. La descripción de estos procesos se remite al trabajo en análisis.

Además - o debido a eso-, desde las décadas de 1940-1950, a la vida religiosa femenina tradicional se fue sobreponiendo una vida religiosa más abierta, en sintonía con el movimiento de renovación de la Iglesia Católica que culminó en el Concilio Vaticano II. Una microevidencia en la Congregación de las Hermanas Misioneras de Jesús Crucificado es el caso ejemplar de la bahiana Marina Luiza Camandaroba. Por ser negra fue recibida como postulante oblata en 1942 e hizo sus primeros votos religiosos en 1945. Educada en un colegio católico y con diploma de Magisterio (curso normal), Marina encontró muy extraña la vida de oblata y, en 1955, reivindicó un cambio de clase. La versión oficial dice que ella «fue trasladada a la clase de las misioneras [hermanas de coro], por la desconformidad de la familia con la condición de la hermana mencionada, quien además tiene suficiente preparación y diploma de normalista» (Beozzo et al., 2009: 201). Aun así, Marina tuvo que rehacer el noviciado y la profesión religiosa, y la profesión perpetua solo se produjo en 1962. ¡Fueron necesarios exactamente veinte años para ser reconocida como una verdadera misionera!

En términos institucionales, en la Congregación de las Misioneras de Jesús Crucificado estos nuevos contextos se reflejaron en la decisión de unificar las clases de hermanas en 1965, proceso que se extendió hasta 1970. En el período de implementación de la igualación de religiosas negras (hermanas oblatas) y religiosas blancas (hermanas de coro), el gran desafío fue reparar los efectos de la segregación sufrida por las hermanas negras, su falta de poder y su invisibilidad en torno a cuatro ejes de acción:

[...] la calificación de las antiguas oblatas por el estudio; la posibilidad de realizar actividades apostólicas externas; la participación en las instancias deliberativas de la Congregación con voz y voto, con la posibilidad de asumir cargos de coordinación y dirección; y, quizás el más crucial y difícil de todos, la ruptura de la antigua división del trabajo (lbídem: 271).

Pero la puerta a la ciudadanía religiosa fue algo traumática, ya que, además de no poder participar en la discusión sobre su futuro, las exoblatas tendrían que rehacer el noviciado y la profesión religiosa, como sucedió con Marina, mencionada anteriormente. Como era de esperar, hubo extrañeza entre las exo- 
blatas y una intervención de la Sagrada Congregación de Religiosos e Institutos Seculares desde la Santa Sede que desestimó la exigencia de un nuevo noviciado y de nuevos votos en rescripto de mayo de 1966. El plan B de la congregación fue exigir un curso de actualización de cuatro meses de duración, que también estaría dirigido a revitalizar el clima del Vaticano II. Esta solicitud fue bien aceptada; sin embargo, las oblatas que por algún motivo no pudieron participar solo lograron integrarse oficialmente en 1970, lo que a juicio de las hermanas negras hirió el espíritu de equidad del rescripto de la Santa Sede.

Como en el plano de las mentalidades las marcas y prácticas históricas se mueven en la temporalidad de larga duración, el período posterior a la abolición de la clase oblata estuvo permeado por numerosos conflictos raciales que impactaron en las relaciones sociales, causando «malestar a algunas misioneras [coristas] con la unificación de las clases, como puede haber habido disconformidad por parte de las oblatas obligadas a recomenzar el noviciado, como si dejaran de ser religiosas para poder transitar hacia el nuevo régimen de clase única» (Ibídem: 294).

Prueba de este conflicto es el caso de la joven negra Berenice dos Santos Borges, también formada en Magisterio. Ingresó en la congregación en 1964 e hizo su primera profesión en 1966. Dado que la extinción de la clase de hermanas oblatas ocurrió en 1965, sería de esperar que Berenice no sufriera discriminación racial.

Como postulante y novicia, fue un tiempo doloroso. Siempre de lado, sin tareas...no salía de misión y, cuando salía, era solo como acompañante de alguna profesa que necesitaba ir de compras, ir al médico o comprar medicinas. Y eso porque yo conocía Río [Río de Janeiro] muy bien.

Me sentía discriminada, acallada en mis dones (Ibídem: 210).

Según el relato histórico, la congregación puso fin a la división que separaba a las candidatas con pocos estudios de las graduadas, a las domésticas de las intelectuales, a las subordinadas de las mandantes, a las negras de las blancas.

El segundo camino tomado para lograr la unificación de las clases fue abrir posibilidades para que las antiguas oblatas superaran la brecha que existía en cuanto a estudios formales entre oblatas y misioneras. Si bien muchas de las misioneras continuaban sus estudios después de ingresar a la Congregación, la mayoría de las oblatas quedó estancada en el punto al que habían llegado en el momento de su ingreso. La situación empezó a cambiar tras la unificación de las clases (lbídem: 331).

Sin embargo, los testimonios presentan más obstáculos que posibilidades para que las mujeres negras continuaran sus estudios. Aunque no aportan datos estadísticos sobre el grupo de las exoblatas, los relatos indican que todavía había una brecha que separaba a blancas y negras, cultas e incultas, cuestión que pasaría por el tamiz de la autoridad eclesiástica, el visitador apostólico de la Santa Sede. En 1971, él determinaría: 
Las superioras locales deberán promover los estudios de las hermanas hasta la finalización del ginásio ${ }^{5}$ - esta es obviamente de una medida dirigida a las ex oblatas -. A partir del cuarto año, la continuidad de los estudios de las religiosas quedará a criterio del Consejo Provincial, que estudiará cada caso según la planificación o las necesidades de la provincia, habiendo escuchado previamente a la coordinadora local (Ibídem: 336).

En otras palabras, si las mujeres negras querían estudiar podrían hacerlo hasta el gimnasio. Este tipo de discriminación provocó el abandono de algunas hermanas negras, como Francisca Miguel de Jesús, que dejó la Congregación en 1969 porque quería tomar el curso de primaria. Las hermanas negras señalan las causas del abandono de sus compañeras negras o no negras, que alcanzó al $36,1 \%$ de la plantilla de la congregación en el período posterior al Concilio Vaticano II: el capítulo general de 1965 promovió solo la unificación de las clases de hermanas, y frustró las expectativas de reformas más profundas y más rápidas.

En cuanto a la justa división del trabajo que permitiera a todas sin distinción estudiar, hacer apostolado (pastoral) y cuidar de la vida y del hogar:

Muchas ex oblatas cuentan que este período de transición representó una sobrecarga de trabajo, ya que agregaron al trabajo doméstico, que ya hacían, el tiempo para el estudio y para la pastoral, sin ser relevadas en horarios o tareas rutinarias. Otras se quejaban de que en las casas más grandes era difícil que las misioneras de coro se hicieran cargo, de manera eficiente, de las tareas de la casa, compartiendo con las antiguas oblatas la pesada carga de limpiar, cocinar, lavar la ropa, atender la portería, etc. (Ibídem: 348).

Las relaciones raciales en la Congregación de las Hermanas Misioneras de Jesús Crucificado comenzaron a cambiar a partir de la implementación de las directrices del Concilio Vaticano II en América Latina, mediadas por dos conferencias episcopales latinoamericanas.

La primera directriz, deliberada por la conferencia de Medellín (1968), animó a la congregación a desarrollar proyectos de «comunidades insertas» y a enviar a hermanas negras, que comenzaron a experimentar una vida religiosa más abierta y socialmente comprometida en las pequeñas comunidades instaladas en barrios populares. Esta directriz estaba en línea con la opción preferencial por los pobres que fue colocada en el centro del plan pastoral de América Latina, lo que requería que las congregaciones religiosas se trasladaran a las periferias de las ciudades y trabajaran en las comunidades de base, participando en la vida cotidiana del pueblo (Beozzo, 1998). Así, hermanas negras y no negras cambiaron los caserones y las instituciones más estructuradas por viviendas más modestas y más parecidas a las casas de las familias del pueblo - de las que muchas de ellas procedían-, ubicadas en lugares de difícil acceso y de notable precariedad social.

5. En Brasil, el gimnasio - ginásio - era la etapa educativa que seguía a la educación primaria. El gimnasio duraba cuatro años, después de los cuales el estudiante podía ingresar al curso de secundaria. Este sistema cambió en 1971. 
La segunda directriz, que emana de la conferencia de Puebla (1979), posibilitó a las hermanas negras el compromiso con el movimiento negro en la Iglesia católica. Este movimiento surgió a partir de la revisión de la evangelización de los pueblos negros e indígenas realizada por la Iglesia de Brasil en ocasión de la preparación de la conferencia de Puebla. En cuanto a los negros, la discusión llevó a la mesa a representantes del clero negro, hermanas negras y laicos y laicas negros, y reafirmó la opción preferencial por los pobres proclamada en Puebla, quienes pasaron a ser observados en sus diferentes culturas y realidades.

Conscientes y atentas a estos signos de cambio en la Iglesia, varias hermanas negras de Jesús Crucificado participaron en este proceso y contribuyeron a la formación del autodenominado Grupo de União e Consciência Negra, que luego fue rebautizado como Pastoral dos Negros por la Conferencia Nacional de Obispos del Brasil (CNBB) y que hoy se llama Pastoral Afro-brasileña. Liderando el movimiento desde la primera hora de su existencia, sor Maria Raimunda R. Costa asumió la coordinación de la Pastoral dos Negros de 1998 a 2002. El trasfondo de este proceso, revelado por Maria Raimunda, muestra la lucha de los católicos negros por su autonomía y agenciamiento en el seno de la Iglesia.

\footnotetext{
Dijimos que no queríamos que nos controlaran. Queríamos caminar con nuestros propios pies. De la Iglesia queríamos espacios y ecumenismo de base, no de cúpula [...]. Dijimos que no estábamos haciendo un trabajo de credo religioso o partido político. Queríamos ser un grupo ecuménico. No queríamos mucha asesoría, ni de blancos ni de negros. Compartimos los asesores entre nosotros [...]. Queríamos ser respetados, ser considerados. Queríamos que nuestro caminar fuera reconocido como digno. Queríamos dialogar con la CNBB y usar los espacios de la lglesia libremente y que continuemos este canje e intercambio. Queríamos la presencia de la CNBB en nuestras reuniones y nuestra presencia en las suyas (Beozzo et al., 2009: 367-368, 369, 370).
}

El movimiento negro en la Iglesia católica en Brasil fue simultáneo al movimiento negro en la sociedad, que retomó sus luchas históricas en los años setenta y ochenta en el contexto de la articulación de movimientos sociales a favor de la redemocratización del país. Comprometidas con este movimiento, las hermanas negras de Jesús Crucificado comenzaron a afirmar su negritud y a fomentar el compromiso de otras compañeras. Así surgieron los Encontros de Irmãs Negras da Congregação das Missionárias de Jesus Crucificado, una instancia de discusión sobre la negritud y los derechos de las mujeres negras y de todo el pueblo negro brasileño, latinoamericano y caribeño.

Es de destacar que los encuentros de las hermanas negras, como ya se mencionó en la introducción de este artículo, constituyeron un espacio de reflexión sobre la historia de la congregación y de reposicionamiento con relación a la participación de las exoblatas en la fundación del instituto, un logro del movimiento en 1996. A medida que se avanzaba en la reconstrucción histórica, también se avanzaba en el reconocimiento del pasado de las hermanas negras en esta congregación (negado por muchas religiosas). En el informe de la reunión de 2004, por ejemplo, las hermanas comentan: «La asesoría de Beozzo desmitificó lo que todavía se dice de nosotras, que estamos inventando cosas, que eso no existió, que es cosa de nuestra cabeza. La realidad vino a mostrar lo contrario. Lo peor es que en algunas comunidades todavía existe una reali- 
dad semejante» (Ibídem: 480). Por ello, reafirmaron que se debería invertir permanentemente en prácticas y actitudes antirracistas.

El movimiento de las hermanas negras, que ya ha cumplido más de tres décadas, cruzó sus experiencias con las de las comunidades insertas, de manera que se dio una identificación recíproca entre religiosas negras y pueblo negro de la pastoral y de los movimientos populares. En este sentido, algunas relatan que el proceso personal de afirmación de la negritud ocurrió en contacto con comunidades negras. Otras mencionan que la afirmación de la negritud se intensificó en el proceso de llevar al pueblo negro hacia el compromiso social. En cualquier caso, los encuentros de las hermanas negras tejieron la construcción de pautas emancipadoras y la valoración de lo históricamente negado: «Somos descendientes de un pueblo esclavizado, pero también somos descendientes de reyes y reinas, tenemos que asumir nuestra historia", fue uno de los objetivos esbozados en la reunión de 1988 (Ibídem: 397).

Ciertamente, no fue nada fácil seguir ese proyecto de vida. Como concluyó Saidiya Hartman (2007: 18), investigadora afroamericana que viajó a Ghana (África Occidental) en busca de las cenizas de su pasado esclavizado, el intento de comprender cómo se inició el suplicio de la esclavitud puede llevar a la siguiente conclusión: «Soy el recuerdo de 12 millones que cruzaron el Atlántico y el pasado aún no terminó. Soy descendiente de cautivos. Soy un vestigio de los muertos. Y la historia es cómo el mundo secular presta atención a los muertos». Cabe mencionar que la investigación de Hartman indica que si una persona afro-descendiente viaja a África con la esperanza de rescatar alguna identidad original se sentirá decepcionada porque las identidades cambian con el tiempo, es decir, se rehacen constantemente, ya que son producto de la historia y de las relaciones sociales. En la misma línea, las hermanas negras de Jesús Crucificado saben mejor que nadie lo que fue rehacer su identidad y, por ello, luchar por su ciudadanía religiosa. Una lucha que parece no tener fin... La pedagoga y antropóloga Maria de Lourdes Siqueira y el sacerdote Antônio Aparecido da Silva, que asistieron al II Encuentro de las Hermanas Negras de Jesús Crucificado, realizado en 1988, afirman que:

\footnotetext{
Tenemos que recuperar, como mujeres negras y como hombres negros, la ciudadanía. Es difícil para el blanco establecer relaciones de igualdad con el pueblo negro: se alcanzan arreglos, pero no se mezclan. La acción de la Iglesia siempre reforzó el sistema colonizador [...]. Ser negra o negro en Brasil es una de las cosas más crueles, a causa del racismo, que es muchas veces camuflado [...].

Nuestra lucha no es contra nadie. Es, sí, contra el racismo, la discriminación, la falta de respeto a la dignidad humana [...]. La presencia de más de cien Hermanas Negras reunidas significa que somos más fuertes que el sufrimiento (Beozzo et al., 2009: 402-403).
}

\section{Observaciones finales}

En términos más amplios, el análisis de la narrativa histórica de las hermanas negras de la Congregación de las Hermanas Misioneras de Jesús Crucificado revela un racismo religioso que puede contextualizarse en el ámbito de la cons- 
trucción sociocultural que tuvo lugar en Brasil: se trata de un país de una gran diversidad cultural, pero con una histórica desigualdad de clase, raza y género que impregnó la construcción de una identidad nacional supuestamente homogénea y eurocéntrica, que afectó a todas las instituciones sociales, incluidos los grupos religiosos.

En el ámbito de la vida religiosa femenina, a pesar de las innovaciones aportadas por el Concilio Vaticano II y las conferencias episcopales latinoamericanas, y a pesar del avance del movimiento negro en la Iglesia católica y en la sociedad brasileña, que condujo a una serie de políticas afirmativas y de acciones antirracistas, aún se observan prácticas que fortalecen los privilegios de la blanquitud. Por ejemplo, en la Congregação das Irmãzinhas da Imaculada Conceição (fundación brasileña), la primera joven negra profesó recién en 1971 (hermana Lucília da Silva, número 1161 del instituto). Evidentemente, antes que ella hubo alguna que otra joven afrodescendiente que hizo sus votos siempre y cuando no tuviese rasgos muy acentuados de negritud. Sin embargo, hasta la fecha, ninguna hermana negra, indígena o parda ha sido elegida superiora general de la congregación desde la constitución del primer gobierno general, en 1903. Por lo tanto, durante ciento diecisiete años el cargo ha estado ocupado por inmigrantes italianas y descendientes de inmigrantes europeos establecidos en el sur y sudeste del Brasil (de las doce hermanas elegidas, solo una era de São Paulo - Sudeste). ${ }^{6}$

Para romper con este tipo de prácticas, es necesario señalar que el lugar de habla de las hermanas negras de Jesús Crucificado «no se limita al acto de emitir palabras» - como lo hicieron valientemente en su História das Irmãs Negras e Indígenas Missionárias de Jesus Crucificado, la obra analizada en este ensayo - sino «para poder existir» (Ribeiro, 2019a: 64). Lo mínimo que se debería hacer $-y$ esta no es una actitud fácil, especialmente para las personas blancas - es escuchar y comprender que «las narrativas de aquellos que fueron forzados a ocupar el lugar del Otro [...] apuntan a generar conflictos necesarios para el cambio» (Ibídem: 78). ${ }^{7}$

Hermoso trabajo para la historia habitual. Rompe el silencio y evita que el racismo sea olvidado y borrado de la memoria congregacional al mismo tiempo que estimula la vigilancia de las conquistas.

6. Datos históricos del Archivo de Historia de la Congregación de las Hermanitas de la Inmaculada Concepción (São Paulo), publicados en 1990: Coletânea Histórica da Congregação das Irmãzinhas da Imaculada Conceição, págs. 31-65, 235.

7. La cursiva en el original. 


\section{Bibliografía}

AlmeidA, Silvio (2019). Racismo estrutural. São Paulo: Pólen. Coleção Feminismos Plurais.

Azzı, Riolando (2008). «A marginalização social dos negros». En: História da lgreja no Brasil: ensaio de interpretação a partir do povo (Terceira Época, 1930-1964). Petrópolis: Vozes, págs. 74-91.

BEAuvouir, Simone de (2009). O segundo sexo. Río de Janeiro: Nova Fronteira.

BEOZzo, José Oscar (1983). «Decadência e morte, restauração e multiplicação das ordens e congregações religiosas no Brasil: 1870-1930». En: Azzı, Riolando. A vida religiosa no Brasil: enfoques históricos, vol. 5. São Paulo: Paulinas, págs. 85-129.

BEOzzo, José Oscar (1998). «Medellín: inspiração e raízes». Revista Eclesiástica Brasileira, Petrópolis, n. 232, págs. 1-21.

BEOzzo, José Oscar et al. (2009). Tecendo memórias, gestando futuro: história das irmãs negras e indígenas missionárias de Jesus Crucificado. São Paulo: Paulinas.

CARneIRo, Sueli (1995). «Gênero, raça e ascensão social». Revista Estudos Feministas, Florianópolis, 2 (3), págs. 544-552.

Collins, Patricia Hill (2019). Pensamento feminista negro. São Paulo: Boitempo.

CustóDıo, Maria Aparecida Corrêa (2011). Artes de fazer de uma congregação católica: uma leitura certeausiana da formação e trajetória das Filhas da Imaculada Conceição (1880-1909). Tesis de doctorado en Educación, Universidade de São Paulo, São Paulo.

Feminismos Plurais. Recuperado en: https://feminismosplurais.com.br/.

FonsECA, Dagoberto José (2000). Negros corpos (i)maculados: mulher, catolicismo e testemunho. Tesis de doctorado en Ciencias Sociales, Pontifícia Universidade Católica de São Paulo, São Paulo.

GINZBURG, Carlo (1989). «Sinais. Raízes de um paradigma indiciário». En Mitos, emblemas, sinais: morfologia e história. São Paulo: Companhia das Letras, págs. 143-179.

GonzALEZ, Lélia (1984). «Racismo e sexismo na cultura brasileira». Revista Ciências Sociais Hoje, Anpocs, São Paulo, págs. 223-244.

GonZALEZ, Lélia (2011). «Por um feminismo afro-latino-americano». En: Batalha de ideias, Caderno de Formação Política do Círculo Palmarino, págs. 12-20. Recuperado en: https://edisciplinas.usp.br/pluginfile.php/271077/mod_resource/content/1/Por\%20 um\%20feminismo\%20Afro-latino-americano.pdf.

HallbWachs, Maurice (2017). A memória coletiva. São Paulo: Centauro.

HARTMAN, Saidiya (2007). Lose your mother. A journey along the Atlantic slave route. Nueva York: Farrar, Straus and Giroux.

KILOMBA, Grada (2019). Plantation memories: episodes of everyday racism. Munster: Unrast.

MACIEL, Cleber da Silva (1985). Discriminações raciais: negros em Campinas (1888-1926) alguns aspectos. Tesis de Maestría en Historia, Unicamp, Campinas.

RıbeIRo, Djamila (2019a). Lugar de fala. São Paulo: Pólen, Coleção Feminismos Plurais.

RıBeIRo, Djamila (2019b). Pequeno manual antirracista. São Paulo: Companhia das Letras.

SILVA, Lindinalva Gomes da (2016). Um estudo sobre as Missionárias de Jesus Crucificado, movimentos de mulheres e movimentos feministas. Tesis de Maestría en Historia, Pontifícia Universidade Católica de Goiás, Goiânia. 
TIEDE, Lívia Maria (2018). «Os homens de cor invisíveis da imprensa negra paulistana: como a biografia de um intelectual negro nascido no século dezenove auxilia a repensar a historiografia do pós-abolição paulistano». Intellèctus, Río de Janeiro, 1 (17), págs. 48-72. Recuperado en: www.e-publicacoes.uerj.br/index.php/intellectus/article/view/33687.

VILLAC, Sylvia Maria do Calvário (1953). O problema racial em função do recrutamento da vida religiosa. Río de Janeiro, obra mimeografiada.

Fecha de recepción: 6 de enero de 2021

Fecha de aceptación: 8 de marzo de 2021

Fecha de publicación: 30 de junio de 2021 